\title{
Progestin content and biosynthetic potential of the corpus luteum of the African elephant (Loxodonta africana)
}

\author{
J. K. Hodges ${ }^{1}$, R. J. van Aarde ${ }^{2}$, M. Heistermann ${ }^{1}$ and H-O. Hoppen ${ }^{3}$ \\ ${ }^{1}$ Department of Reproductive Biology, German Primate Centre, Kellnerweg 4, 37077 Göttingen, Germany; \\ ${ }^{2}$ Mammal Research Institute, University of Pretoria, Pretoria 0002, South Africa; and ${ }^{3}$ Chemisches \\ Institut der Tierärztlichen Hochschule, Bischofsholer Damm, 30173 Hannover, Germany
}

\begin{abstract}
The aim of this study was to examine the progestin content and biosynthetic potential of the corpus luteum of the African elephant (Loxodonta africana). Luteal tissue was collected from nonpregnant and early, mid- and late pregnant elephants ( $n=2$ per group) shot in the Kruger National Park. Pieces of individual corpora lutea (2-3 per animal; 23 in total) were stored directly in ethanol before hormone analysis. Matching tissue pieces were incubated for $2 \mathrm{~h}$ with $\left[^{3} \mathrm{H}\right]$ pregnenolone $\left(2 \times 10^{5}\right.$ c.p.m.), after which tissue plus medium were also stored in ethanol. Progesterone and 17 $\alpha$-hydroxyprogesterone immunoreactivity in tissue extracts were determined by enzymeimmunoassay and radioimmunoassay, respectively, before and after reverse phase HPLC. Progesterone immunoreactivity predominated over that of $17 \alpha$-hydroxyprogesterone in all corpora lutea examined but concentrations of both hormones were very low $\left(73-374 \mathrm{ng} \mathrm{g}^{-1}\right.$ and $3-93 \mathrm{ng} \mathrm{g}^{-1}$, respectively after HPLC). There were no obvious differences in hormone concentrations in corpora lutea from animals at different reproductive stages. Progesterone and $17 \alpha$-hydroxyprogesterone immunoreactivity assayed before HPLC was 10-30 times higher than that measured after chromatographic separation. HPLC consistently revealed two large immunoreactive peaks associated with relatively nonpolar compounds, which together accounted for most (at least $75 \%$ ) of all progesterone immunoreactivity measured. Large amounts of radioactivity with the same retention times as these peaks were also detected after HPLC in samples incubated with $\left[{ }^{3} \mathrm{H}\right]$ pregnenolone. Analysis of conversion products from four corpus luteum incubations indicated that between $52 \%$ and $84 \%$ of $\left[{ }^{3} \mathrm{H}\right]$ pregnenolone had been converted; $19-33 \%$ was accounted for by progesterone, and $12-50 \%$ by the two substances represented by the unidentified peaks. Subsequent GCMS analysis identified the two immunoreactive peaks as $5 \alpha$-pregnane-3 $\alpha$-ol-20-one and $5 \alpha$-pregnane-3,20-dione ( $5 \alpha$-dihydroprogesterone). These results indicate that the major progestins contained within and biosynthesized by corpora lutea of African elephants are $5 \alpha$-reduced metabolites, and that progesterone and $17 \alpha$-hydroxyprogesterone are quantitatively of minor importance.
\end{abstract}

\section{Introduction}

The African elephant, Loxodonta africana (like its Asian counterpart) is listed in Appendix 1 of Cites as an endangered species. An understanding of its reproductive physiology is therefore not only of comparative interest, but is also of practical importance for the development of more effective strategies for the breeding and long-term management of the species.

Knowledge of the endocrinology of reproduction in African elephants is, however, superficial. For instance, although measurement of circulating hormones has been used to monitor the ovarian cycle and pregnancy (Hodges et al., 1983; McNeilly et al., 1983; Brannian et al., 1988; Plotka et al., 1988), the factors controlling the formation and functions of the corpus luteum

Received 24 February 1994 are unknown. On the basis of calving rate (Laws, 1969) and the report of a single ovulation in an early post-oestrus animal (Short, 1966), the African elephant would appear to be monovular, yet ovaries of both cyclic and pregnant animals almost invariably contain multiple corpora lutea, many of which possess ovulation stigmata (Laws, 1969; Hanks and Short, 1972; Smith and Buss, 1975). How and when these corpora lutea are formed and what controls their functional lifespan remain to be determined.

Early studies by Short and colleagues also raised questions concerning the steroidogenic function of the corpus luteum of the African elephant. Concentrations of progesterone determined by gas chromatography were either undetectable (Short and Buss, 1965; Short, 1966) or extremely low (Smith et al., 1969); the progesterone content of the single elephant corpus luteum determined by Smith et al. was 2-3 orders of magnitude lower than in other mammals. Measurements of 
immunoreactive progesterone in serum have been reported (see above), but the concentrations are low (generally $<2 \mathrm{ng}$ $\mathrm{ml}^{-1}$ ) and appear not to correlate with total corpus luteum volume (de Villiers et al., 1989).

The aims of the study reported here were to clarify the steroidogenic function of the African elephant corpus luteum by (i) determining the concentrations of immunoreactive progesterone and 17a-hydroxyprogesterone in individual corpora lutea from pregnant and nonpregnant animals and (ii) investigating the potential of the corpus luteum for biosynthesis of other progestins.

\section{Materials and Methods}

\section{Animals}

The studies used ovarian tissue collected from adult female elephants (two nonpregnant and six pregnant) shot for management purposes in the Kruger National Park during May 1990. Embryonic or fetal masses were used to select two animals each from early $(0.001$ and $0.008 \mathrm{~kg})$, mid- (29.0 and $35.5 \mathrm{~kg}$ ) and late (81.I and $121.0 \mathrm{~kg}$ ) stages of gestation. The two nonpregnant animals for which results are reported were lactating.

\section{Tissue collection and field laboratory protocol}

Ovary dissection and corpus luteum removal. Ovaries $(n=8$ pairs) were removed within $30 \mathrm{~min}$ of death and placed on ice for transport to the field laboratory. The largest luteal structures (usually $2-3$ per animal; 23 in total) were carefully dissected from the ovary, trimmed of extraneous tissue and weighed. The corpora lutea analysed in this study were pinkish-yellow (elephants that were not pregnant or in early and mid pregnancy) or pale brown (late pregnancy), and ranged between 1.2 and $5.0 \mathrm{~cm}$ in diameter.

Slices of tissue of approximately $500 \mathrm{mg}$ (individual masses were recorded accurately) were placed in duplicate glass vials containing $10 \mathrm{ml}$ absolute ethanol. Additional pieces of tissue from each corpus luteum were also used in incubation studies with radiolabelled pregnenolone (see below) before storage in ethanol. All ovarian dissections and tissue incubations were completed within 6-8 h of ovary removal. Samples were kept in the field at $-10^{\circ} \mathrm{C}$, transported to the German Primate Centre, Göttingen on dry ice and then stored at $-20^{\circ} \mathrm{C}$ until analysis.

Corpus luteum incubation studies. Incubation studies were carried out on tissue slices from each of the 23 corpora lutea using $\left[4,7-{ }^{3} \mathrm{H}\right]$ pregnenolone (specific activity, $49.3 \mathrm{mCi} \mathrm{mg}^{-1}$; radiochemical purity, $98 \%$; Amersham International, Amersham) as radiolabelled substrate. Tracer was diluted in ethanol and kept at $4^{\circ} \mathrm{C}$ until use (within 2-3 weeks). Each slice of tissue was placed into a glass scintillation vial containing $2 \mathrm{ml}$ freshly made Eagle's minimum essential medium ( $\mathrm{pH}$ 7.4), containing $25 \mathrm{mmol}$ Hepes $\mathrm{I}^{-1}$ and $7.5 \%$ sodium bicarbonate. A volume of $50 \mu \mathrm{l}\left[{ }^{3} \mathrm{H}\right]$ pregnenolone (approximately $2 \times$ $10^{5}$ c.p.m.) was added, and the contents of the vial were gently mixed and the vials incubated in a shaking water bath at $37^{\circ} \mathrm{C}$ for $2 \mathrm{~h}$. At the end of the incubation, $8 \mathrm{ml}$ ice-cold ethanol was added, the contents well mixed and the vials stored at $-20^{\circ} \mathrm{C}$. Vials were prepared for each experiment to determine the amount of radioactive substrate used, and vials containing tracer and medium only (i.e. no tissue) were incubated with the tissue slices to serve as controls.

\section{Sample extraction}

All corpus luteum slices, including those used for tissue incubation studies, were minced with scissors in the original vial containing ethanol and the contents transferred to a glass homogenizing tube. The vial was rinsed with a further $2 \mathrm{ml}$ ethanol and the two volumes combined. Approximately 20000 c.p.m. each of $\left[{ }^{3} \mathrm{H}\right]$ progesterone, $17 \alpha$-hydroxyprogesterone and $20 \alpha$-hydroxypregnenone in $50 \mu \mathrm{l}$ ethanol were added to vials containing samples for hormone assay only to monitor extraction efficiency and steroid elution positions on HPLC. Tissues were homogenized by hand and the contents (including $2 \mathrm{ml}$ ethanol rinse) decanted into a tube for centrifugation at $500 \mathrm{~g}$ for $5 \mathrm{~min}$. The supernatant was transferred to a clean glass tube and reduced in volume to $0.5 \mathrm{ml}$, to which $3.5 \mathrm{ml} 80 \%$ methanol and $1.0 \mathrm{ml} n$-hexane were added. The contents were vortexed, centrifuged at $5000 \mathrm{~g}$ for $10 \mathrm{~min}$ and the methanol phase removed.

For determination of steroid content, one portion of the methanol was evaporated to dryness, reconstituted in $1 \mathrm{ml}$ absolute methanol and diluted in buffer for hormone assay without HPLC; a second portion was evaporated and reconstituted in $250 \mu \mathrm{l}$ acetonitrile:water (50:50) for HPLC. For separation of conversion products of $\left[{ }^{3} \mathrm{H}\right]$ pregnenolone following incubation studies, the methanol phase was evaporated and reconstituted in acetonitrile:water for injection on to HPLC. Mean extraction efficiencies were between 61 and $74 \%$ for progesterone and 17a-hydroxyprogesterone, including the HPLC step $(n=23)$; corresponding figures without HPLC were 77 and $78 \%(n=23)$.

\section{Chromatography}

HPLC. Sample extracts in acetonitrile:water were filtered by passage through a $0.2 \mu \mathrm{m}$ membrane before loading $100 \mu \mathrm{l}$ on to a Nova Pak C18 HPLC column $(3.9 \mathrm{~mm} \times 75 \mathrm{~mm}$ ). Steroids were separated by reverse phase chromatography using an acetonitrile:water mixture (38:62) as eluent at a flow rate of $1 \mathrm{ml} \mathrm{min}{ }^{-1}$ (Heistermann et al., 1993). Fractions were collected at $1 \mathrm{~min}$ intervals and an aliquot of each was either counted directly (tissue incubation study) or evaporated to dryness and reconstituted in buffer for recovery determination and hormone assay.

TLC. Since pregnenolone and progesterone could not be separated using the above HPLC system, the fractions containing these steroids (usually 20-24; see Fig. I) were pooled, evaporated to dryness and reconstituted in $100 \mu$ l ethanol, from which duplicate $40 \mu \mathrm{l}$ aliquots were combined with $1 \mathrm{ng}$ of each steroid as carriers and subjected to TLC (incubation study only). The two steroids were separated using Silica 60 F254 plates $(20 \mathrm{~cm} \times 20 \mathrm{~cm} ; 0.25 \mathrm{~mm}$ thick; Merck, Darmstadt) and a mixture of chloroform:ethyl acetate $(9: 1, \mathrm{v}: \mathrm{v})$ as the mobile phase. As reference and recovery control, duplicate 
Table 1. Progesterone and $17 \alpha$-hydroxyprogesterone immunoreactivity in individual corpora lutea from nonpregnant and pregnant elephants as determined before and after an HPLC purification step

\begin{tabular}{|c|c|c|c|c|c|c|c|c|}
\hline \multirow[b]{2}{*}{ Animal } & \multirow{2}{*}{$\begin{array}{l}\text { Reproductive } \\
\text { status }\end{array}$} & \multirow{2}{*}{$\begin{array}{l}\text { Fetal mass } \\
\quad(\mathrm{kg})\end{array}$} & \multicolumn{2}{|c|}{ Corpus luteum } & \multicolumn{2}{|c|}{ Progesterone (ng $\mathrm{g}^{-1}$ ) } & \multicolumn{2}{|c|}{ 17a-Hydroxyprogesterone $\left(\mathrm{ng} \mathrm{g}^{-1}\right)$} \\
\hline & & & Identity & Mass (g) & With HPLC & Without HPLC & With HPLC & Without HPLC \\
\hline \multirow[t]{3}{*}{462} & Nonpregnant & - & ${\mathrm{L} 1^{\mathrm{a}}}$ & 15.7 & 309.8 & 9769.0 & 43.5 & 603.3 \\
\hline & & & L 2 & 4.8 & 107.5 & 1264.3 & 5.0 & 160.4 \\
\hline & & & $\mathrm{R}^{\mathrm{a}}$ & 4.3 & 72.7 & 931.8 & 2.6 & 145.6 \\
\hline \multirow[t]{2}{*}{451} & Early pregnant & 0.001 & L I & 33.1 & 206.0 & 4211.8 & 64.6 & 367.1 \\
\hline & & & $\mathrm{R}$ & 8.8 & 232.3 & 3754.6 & 92.9 & 408.3 \\
\hline \multirow[t]{4}{*}{495} & Mid-pregnant & 35.5 & L 1 & 12.9 & 163.4 & 3671.6 & 13.9 & 118.0 \\
\hline & & & L 2 & 5.6 & 128.5 & 3273.5 & 8.5 & 265.3 \\
\hline & & & R 1 & 23.0 & 261.8 & 6390.1 & 33.5 & 541.0 \\
\hline & & & R 2 & 7.9 & 153.4 & 4374.0 & 17.4 & 376.4 \\
\hline \multirow[t]{2}{*}{465} & Late pregnant & 81.0 & L 1 & 18.3 & 355.7 & 3274.6 & 35.3 & 314.7 \\
\hline & & & L 2 & 15.2 & 373.8 & 2262.6 & 48.3 & 347.9 \\
\hline
\end{tabular}

${ }^{a} \mathrm{~L}$ and $\mathrm{R}$ indicate left and right ovaries, respectively.

$40 \mu \mathrm{l}$ volumes of a mixture of $\left[{ }^{3} \mathrm{H}\right]$ pregnenolone and progesterone (approximately 10000 c.p.m.) were also included on the TLC plate. After $50 \mathrm{~min}$, steroid positions were identified by absorption of ultraviolet light or by spraying with $3 \mathrm{~mol}$ $\mathrm{H}_{2} \mathrm{SO}_{4} 1^{-1}$ and drying at $110^{\circ} \mathrm{C}$ for $10 \mathrm{~min}$. The silica containing the separated steroids was scraped from the plates and radioactivity determined by liquid scintillation counting. Recovery values were 89 and $85 \%$ for progesterone and pregnenolone, respectively.

Gas chromatography, mass spectrometry (GCMS), Identification of steroids eluted from HPLC was achieved by GCMS analyses with a SSQ-710 mass spectrometer coupled to a varian 3400 gas chromatograph, using spitless injection (Finnigan MAT Instruments, Bremen). The GC column (30 m fused silica capillary column, inner diameter of $0.25 \mathrm{~mm}$, with DB-5 MS as the stationary phase; J and W Scientific, Folson, CA) was operated at $25 \mathrm{psi}$ helium, a temperature programme of $100-270^{\circ} \mathrm{C}$, an injector temperature of $260^{\circ} \mathrm{C}$ and a transfer line temperature of $250^{\circ} \mathrm{C}$. Electron impact positive ionization was used at $70 \mathrm{eV}$.

\section{Hormone assays}

Progesterone was measured in corpus luteum extracts either directly or after HPLC. For determination of immunoreactive profiles such as those in Fig. I, an aliquot of each reconstituted HPLC fraction was diluted appropriately and assayed. For determination of tissue content (Table 1), HPLC fractions containing $\left[{ }^{3} \mathrm{H}\right]$-labelled tracer were combined before being evaporated, reconstituted in buffer and assayed.

Progesterone was measured by enzymeimmunoassay using an antiserum raised in a sheep against progesterone 11a-hemisuccinate-BSA and alkaline phosphatase linked to progesterone-11-glucuronide as enzyme conjugate (Hodges et al., 1988; Heistermann et al., 1993). The crossreactivity of the antiserum (relative to progesterone) was $11 \alpha-$ hydroxyprogesterone, $\quad 74 \%$; 5 -pregnen-3,20-dione, $43 \%$; $17 \alpha$-hydroxyprogesterone, $1.3 \% ; 20 \alpha$-hydroxypregnenone,
$<0.4 \%$; $5 \alpha$-dihydroprogesterone, $14 \%$; pregnenolone, $2.4 \%$; $5 \alpha$-pregnane-3 $\alpha$-ol-20-one, $0.7 \%$; cortisol $<0.1 \%$. Sensitivity of the assay, defined as the hormone concentration at $90 \%$ binding, was $6 \mathrm{pg}$ per tube, and the intra- and interassay coefficients of variation determined at $70 \%$ binding were $7.4 \%$ and $12.5 \%$, respectively. Dilutions of tissue extracts both with and without purification by HPLC gave displacement curves parallel to that of the standard.

$17 \alpha$-Hydroxyprogesterone was determined before and after HPLC by a $\left[{ }^{3} \mathrm{H}\right]$ radioimmunoassay method described by Hodges et al. (1983). The antiserum used was raised in a rabbit against $17 \alpha$-hydroxyprogesterone-3-O-(carboxymethyl)oximeBSA (Steranti Research Ltd, St Albans) and showed the following crossreactivites: progesterone, 1.4\%; 5 -pregnen-3,20dione, $0.7 \%$; $5 \alpha$-pregnane-3,20-dione, $0.2 \%$; $5 \alpha$-pregnane$3 \alpha$-ol-20-one, $0.08 \%$; 11 $\alpha$-hydroxyprogesterone, 20 $\alpha$-hydroxypregnenone and cortisol, $<0.1 \%$. Sensitivity of the assay at $90 \%$ binding was 18 pg per tube and intra- and interassay coefficients of variation determined at $65 \%$ binding were 8.9 and $12.6 \%$, respectively. Serial dilutions of tissue extracts before and after HPLC gave displacement curves parallel to that of the $17 \alpha$-hydroxyprogesterone standard.

\section{Results}

\section{Luteal immunoreactive progestin content}

Results of analysis of tissue from one animal from each of the four reproductive stages are shown (Table I) and similar results were obtained in the other animals. Concentrations of immunoreactive progesterone exceeded those of $17 \alpha$-hydroxyprogesterone in all samples assayed, irrespective of whether HPLC was performed. Except for one of the nonpregnant animals (462), marked differences between progestin concentrations in individual corpora lutea within an animal were not found and there were no consistent differences between animals in the various reproductive states. However, clear and consistent differences were seen before and after HPLC. Concentrations of both progesterone and 17a-hydroxyprogesterone were up to 30 times higher in corpus luteum 

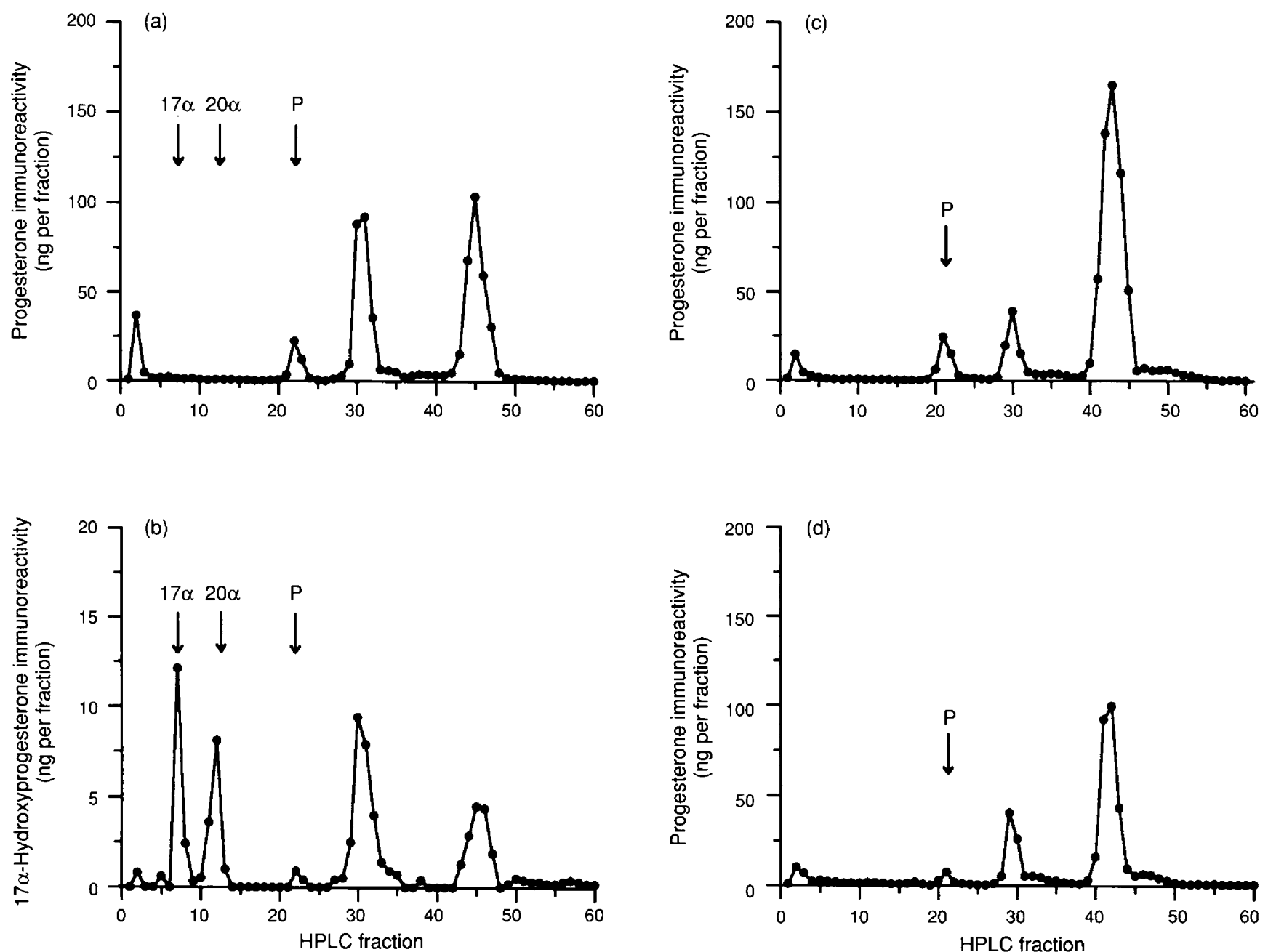

Fig. 1. HPLC profiles of (a) progesterone and (b) $17 \alpha$-hydroxyprogesterone immunoreactivity in a corpus luteum extract from an early-pregnant elephant, and of progesterone immunoreactivity in extracts from a (c) nonpregnant and (d) mid-pregnant animal. Arrows indicate the elution

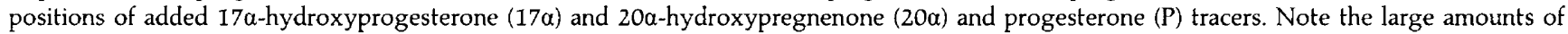
immunoreactivity around fractions $29-32$ and $41-47$, with similar peak retention times relative to progesterone (1.4 and 2.0$)$ in all HPLC profiles. These peaks have been designated $\mathrm{A}$ and $\mathrm{B}$, respectively.

extracts measured directly compared with those made after HPLC, suggesting the presence of large amounts of other immunoreactive progestins. The more specific values obtained after HPLC indicate that luteal progesterone concentrations range from 73 to $374 \mathrm{ng} \mathrm{g}^{-1}$, while those for $17 \alpha$-hydroxyprogesterone range from 3 to $93 \mathrm{ng} \mathrm{g}^{-1}$.

The nature of the substances contributing to total progestin immunoreactivity was examined in one corpus luteum extract from each of the eight animals. Immunoreactive profiles were generated by assaying each of the 60 fractions from HPLC for both progesterone and $17 \alpha$-hydroxyprogesterone. Results for one of the early pregnant animals (451; Fig. 1a, b) indicated low concentrations of progesterone and $17 \alpha$-hydroxyprogesterone, but substantial amounts of immunoreactivity that did not co-elute with the added tracers. This material was found predominantly in fractions $29-33$ and $43-47$ in both assays. The well-defined peaks (designated $A$ and $B$, respectively) suggest the presence of two relatively nonpolar compounds that together represent the majority of the total immuno- reactivity detected. Similar peaks can also be seen in HPLC profiles of progesterone immunoreactivity in corpus luteum extracts from a nonpregnant (462) and mid-pregnant animal (495) (Fig. Ic, d, respectively). Expressed as a percentage, the two relatively nonpolar peaks together accounted for $89.2 \pm 2.0 \%$ (mean \pm SEM) of the total progesterone immunoreactivity measured in the eight luteal extracts analysed.

\section{Tissue conversion of $\left[^{3} H\right]$ pregnenolone}

Conversion products of radiolabelled pregnenolone were examined in one corpus luteum from each of the eight animals. The HPLC profiles of radioactivity from samples from a mid(495) and late (465) pregnant animal are shown (Fig. 2). In the control, radioactivity is confined to fractions $21-24$, corresponding to the elution position of pregnenolone. After incubation with tissue, small amounts of radioactivity were found at the elution position of $17 \alpha$-hydroxyprogesterone 


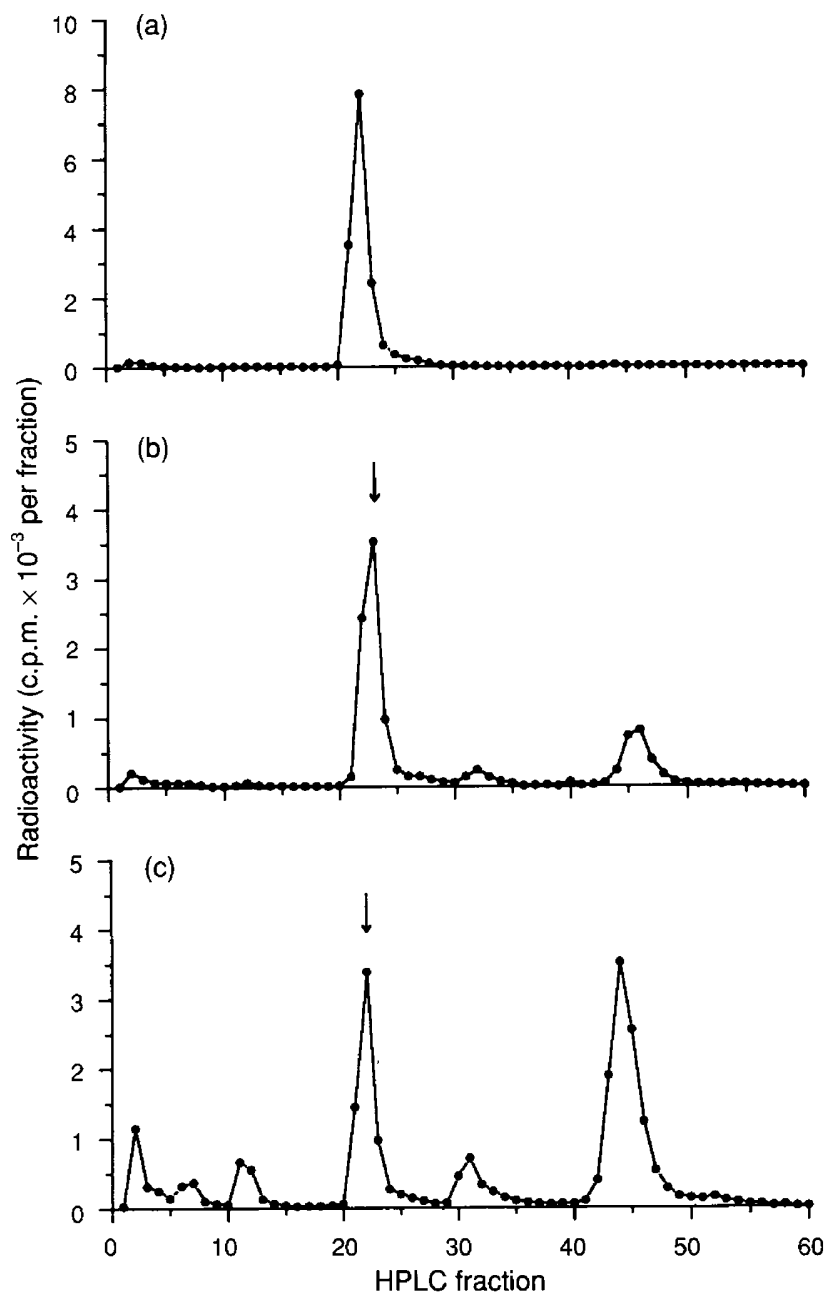

Fig. 2. HPLC profile of radioactivity after incubation of (a) medium only (i.e. no luteal tissue; control), and of luteal tissue from (b) a mid-pregnant and (c) late pregnant elephant with $\left[{ }^{3} \mathrm{H}\right]$ pregnenolone for $2 \mathrm{~h}$. Note that the arrows indicate the elution position of both progesterone and pregnenolone. Thus, in (b) and (c) these peaks of radioactivity have the same retention times relative to that of progesterone (1.4 and 2.0) as do the two peaks of immunoreactivity ( $A$ and $B$ ) in the profiles shown in Fig. 1.

(fractions 6-7) and 20a-hydroxypregnenone (fractions 11-12), but most was detected in fractions $30-33$ and 43-47, corresponding to peaks A and B described above. Significantly, most immunoreactivity (an aliquot of each HPLC fraction was also assayed for progesterone) was also found in the fractions containing most of the radioactivity (30-33 and 43-47), and these two peaks of radioactivity were measured in each of the eight corpus luteum extracts.

Quantitative assessment of pregnenolone conversion could not initially be made because progesterone was found to co-elute with pregnenolone in the HPLC system used. This was overcome by applying the progesterone- and pregnenolonecontaining fractions to TLC. Of the four samples analysed in this way, $35.5,49.4,67.6$ and $76.1 \%$ of the counts in fractions 21-24 had the same mobility as that of progesterone, and the remaining counts were accounted for by pregnenolone. In contrast, $<1 \%$ of the radioactivity from the controls did not co-elute with pregnenolone. The combined results of sequential HPLC and TLC separation are shown (Table 2).

\section{GCMS confirmation of progesterone and identification of HPLC peaks $A$ and $B$}

Fractions containing immunoreactivity corresponding to peaks $A$ and $B$ were collected from the tissue extracts of four animals, pooled and analysed by GCMS. Peak A was found to contain a single steroid with a molecular mass $(318 \mathrm{kDa})$, fragmentation pattern and GC retention time identical to those of $5 \alpha$-pregnane-3 $\alpha$-ol-20-one. Peak B contained a single steroid with a molecular mass $(316 \mathrm{kDa})$, fragmentation pattern and GC retention time identical to those of $5 \alpha$-pregnane-3,20dione. The presence of progesterone in fractions 20-24 was confirmed, although the most abundant steroid identified was pregnenolone.

\section{Discussion}

The principal objective of this study was to examine the progestin content and biosynthetic potential of the corpus luteum of the African elephant. The results show that, quantitatively, progesterone is of minor significance and that the most abundant progestins contained within and biosynthesized by the African elephant corpus luteum are $5 \alpha$-pregnane- $3 \alpha$-ol20-one and 5 $\alpha$-pregnane-3,20-dione.

The only previous information on the progesterone content of the corpus luteum of African elephants derives from a single determination by gas chromatography of early pregnancy tissue, in which a concentration of $180 \mathrm{ng} \mathrm{g}^{-1}$ tissue was found. This value falls within the range described here (3-374 $\mathrm{ng} \mathrm{g}^{-1}$ ) for immunoreactive progesterone in corpora lutea measured after HPLC, although the absolute values may be slight overestimates owing to possible contamination with pregnenolone. The present results do, however, confirm the original findings of Short that the progesterone content of the African elephant corpus luteum is extremely low and in contrast to that reported for other mammals (Short and Buss, 1965; Short, 1966).

Circulating concentrations of $17 \alpha$-hydroxyprogesterone comparable to those of progesterone have been reported in the African elephant (McNeilly et al., 1983) and recent results for the Asian species point to general similarities in the profiles for the two steroids during the ovarian cycle and pregnancy (Niemuller ef al., 1993). The present results indicate that although $17 \alpha$-hydroxyprogesterone can be measured in all luteal extracts examined, the amounts were approximately 10-20 times lower than those of progesterone. 17 $\alpha$-Hydroxy. progesterone is therefore unlikely to be of quantitative importance as a secretory product of the African elephant corpus luteum, although the relative contributions to circulating concentrations of direct ovarian secretion and peripheral metabolism are not known.

Large amounts of the $5 \alpha$-reduced metabolites $5 \alpha$-pregnane$3 \alpha$-ol-20-one and 5a-dihydroprogesterone were detected in all corpus luteum extracts examined, and together were found to represent most of the total immunoreactivity measured. However, reliable figures for the relative amounts of the two steroids cannot be given. Of the two HPLC peaks referred to, 
Table 2. Conversion of $\left[{ }^{3} \mathrm{H}\right]$ pregnenolone by luteal tissue from four individual elephants

\begin{tabular}{llccccc}
\hline Animal & $\begin{array}{c}\text { Reproductive } \\
\text { status }\end{array}$ & $\begin{array}{c}\text { Progesterone } \\
(\%)\end{array}$ & $\begin{array}{c}\text { Peak A } \\
(\%)\end{array}$ & $\begin{array}{c}\text { Peak B } \\
(\%)\end{array}$ & $\begin{array}{c}\text { Rest } \\
(\%)\end{array}$ & $\begin{array}{c}\text { Total conversion } \\
(\%)\end{array}$ \\
\hline 462 & Non-pregnant & 33.4 & 9.9 & 25.0 & 15.6 & 83.9 \\
451 & Early pregnant & 32.4 & 6.1 & 15.8 & 12.5 & 66.8 \\
495 & Mid-pregnant & 26.6 & 3.3 & 8.9 & 12.8 & 51.6 \\
465 & Late pregnant & 18.8 & 7.1 & 42.4 & 25.8 & 84.1 \\
\hline
\end{tabular}

${ }^{a}$ Values are percentages of total radioactivity recovered after HPLC.

The sum of the first four columns reflects total conversion; the remainder (figures not shown) represents unmetabolized pregnenolone.

peak $\mathrm{B}$ was usually higher than peak $\mathrm{A}$ (5a-pregnane-3a-ol-20one), although the crossreactivity of $5 \alpha$-pregnane-3 $3 \alpha$-ol-20-one in the progesterone assay $(0.7 \%)$ was considerably lower than for $5 \alpha$-dihydroprogesterone $(14 \%)$. Higher concentrations of $5 \alpha$-pregnane-3 $\alpha$-ol-20-one were measured by GCMS, although this was after analysis of pooled samples; relative procedural losses for each steroid during the preparative stages cannot be assessed.

Incubation studies showed that $5 \alpha$-reduced progestins are actively synthesized from pregnenolone by the corpus luteum, and since relatively large amounts of radiolabelled progesterone were also formed, it is reasonable to assume that the $5 \alpha$-reduced compounds are metabolites of progesterone. Substantial biosynthesis of $5 \alpha$-reduced progesterone compounds in the adult ovary has not previously been described but has been shown in other tissues including the brain, placenta and endometrium (see for example Karavolas and Hodges, 1990; Moss et al., 1979; Hamon et al., 1991).

The significance of the finding of large amounts of $5 \alpha$-reduced progesterone metabolites in the elephant corpus luteum is unclear. $5 \alpha$-Reduced progestins have been detected in high concentrations in plasma during late pregnancy in mares (Hamon et al., 1991; Holtan et al., 1991), although their function is not known. Given the unusually low concentrations of progesterone found during gestation in the African elephant, it would be of interest to determine whether $5 \alpha$-reduced progesterone metabolites are secretory products of the corpus luteum and whether they have any specific gestagenic actions within the reproductive tract of this species. Studies to address these questions are underway.

The authors thank the authorities of the Kruger National Park for permission to work within the park and to join the elephant cull. In particular they are grateful to I. Whyte for making the necessary arrangement to support our stay in the Kruger, and for his invaluable help with the collection of material. They also thank M. Haup and B. Bauer for excellent technical assistance in the field and laboratory, respectively, and A. Büthe for performing the GCMS analyses. Financial support for the study was provided by the University of Pretoria and by a research grant to R. J. van Aarde by the Foundation for Research Development.

\section{References}

Brannian JD, Griffin F, Papkoff H and Terranova PF (1988) Short and long phases of progesterone secretion during the oestrous cycle of the African elephant (Loxodonta africana) Joumal of Reproduction and Fertility 84 357-365
De Villiers DJ, Skinner JD and Hall-Martin AJ (1989) Circulating progesterone concentrations and ovarian functional anatomy in the African elephant (Loxodonta africana) Journal of Reproduction and Fertility 86 195-201

Hamon M, Clarke SW, Houghton E, Fowden AL, Silver M, Rossdale PD, Ousey JC and Heap RB (1991) Production of $5 \alpha$-dihydroprogesterone during late pregnancy in the mare Journal of Reproduction and Fertility Supplement $\mathbf{4 4}$ $529-535$

Hanks J and Short RV (1972) The formation and function of the corpus luteum in the African Elephant Loxodonta africana Journal of Reproduction and Fertility $2979-89$

Heistermann M, Tari S and Hodges JK (1993) Measurement of faecal steroids for monitoring ovarian function in New World primates, Callitrichidae Journal of Reproduction and Fertility 99 243-251

Hodges JK, Henderson C and McNeilly AS (1983) Circulating oestrogen concentrations during pregnancy in the African elephant (Loxodonta africana) Journal of Reproduction and Fertility 67 121-127

Hodges JK, Green DJ, Cottingham PG, Sauer MJ, Edwards D and Lightman SL (1988) Induction of luteal regression in the marmoset monkey (Callithrix jacchus) by a gonadotrophin releasing hormone antagonist and the effects on subsequent follicular development Journal of Reproduction and Fertility $\mathbf{8 2}$ $743-752$

Holtan DW, Houghton E, Silver M, Fowden AL, Ousey J and Rossdale PD (1991) Plasma progestagens in the mare, fetus and newborn foal Journal of Reproduction and Fertility Supplement 44 517-528

Karavolas HJ and Hodges DR (1990) Neuroendocrine metabolism of progesterone and related progestins Ciba Foundation Symposium 153 22-55

Laws RM (1969) Aspects of reproduction in the African elephant, Loxodonta africana Journal of Reproduction and Fertility Supplement 6 193-217

McNeilly AS, Martin RD, Hodges JK and Smuts GL (1983) Blood concentrations of gonadotrophins, prolactin and gonadal steroids in males and in nonpregnant and pregnant female African elephants (Loxodonta africana) Joumal of Reproduction and Fertility 67 113-120

Moss GE, Estergreen VL, Becker SR and Grant BD (1979) The source of the $5 \alpha$-pregnanes that occur during gestation in mares Journal of Reproduction and Fertility Supplement 27 511-519

Niemuller CA, Shaw HJ and Hodges JK (1993) Monitoring pregnancy in the Asian elephant (Elephas maximus) by urinary and plasma progestin analysis Journal of Reproduction and Fertility Abstract Series 11 Abstract 175

Plotka ED, Seal US, Zarembka FR, Simmons LG, Teare A, Phillips LG, Hinshaw KC and Wildt DG (1988) Ovarian function in the elephant: luteinizing hormone and progesterone cycles in African and Asian elephants Biology of Reproduction 38 309-314

Short RV (1966) Oestrous behaviour, ovulation and the formation of the corpus luteum in the African elephant (Loxodonta africana) East African Wildife Journal 4 56-68

Short RV and Buss IO (1965) Biochemical and histological observations on the corpora lutea of the African elephant, Loxodonta africana Journal of Reproduction and Fertility $961-67$

Smith NS and Buss IO (1975) Formation, function and persistence of the corpora lutea of the Aftrican elephant (Loxodonta africana) Journal of Mammalogy 56 30-43

Smith JG, Hanks J and Short RV (1969) Biochemical observations on the corpora lutea of the African elephant, Loxodonta africana Journal of Reproduction and Fertility 20 111-117 